\title{
Flexible Mental Calculation: Reasoning Profiles of Brazilian Students in Second and Fourth Grades
}

\author{
Sula Cristina Teixeira Nunes \\ Beatriz Vargas Dorneles \\ Luciana Vellinho Corso \\ Universidade Federal do Rio Grande do Sul, Brazil
}

Achieving cognitive flexibility is an essential mathematical competence for students' deep understanding of arithmetic. One approach to research on cognitive flexibility is the work of Rathgeb-Schnierer and Green (2013, 2015, 2017), whose methodology prompted students to exhibit a multitude of flexible strategies in their mental arithmetic and led to the discovery of three flexibility profiles. The research reported here attempts to replicate important elements of the Rathgeb-Schnierer and Green work in a novel population of Portuguese-speaking elementary students. Eighty-four second and fourthgrade Brazilian students were given a translated version of a guided interview with 12 two-digit addition and subtraction problems. Qualitative and quantitative results indicated (a) that the methodology was robust across cultural and linguistic boundaries and $(b)$ that the flexibility patterns reported by Rathgeb-Schnierer and Green were also found with Brazilian elementary students. Some educational implications of research into cognitive flexibility are discussed.

Keywords: cognitive flexibility, mental calculation, reasoning profile

In recent decades, cognitive flexibility has been increasingly studied and received considerable attention in the educational practices of Germany, Portugal, Belgium, Italy, Netherlands, Australia, and the United States as an important competence of the higher-order thinking ability (Verschaffel et al., 2009). In general terms, cognitive flexibility refers to the ability to analyze different resolution approaches in a problem situation, as well as the possibility of dealing with new situations without being attached to predetermined standards, such as the standard computing algorithms. There is empirical evidence that flexibility is a desired ability for both children (Verschaffel et al., 2009) and adults (Torbeyns et al., 2011) and valuable for 
both calculations of the set of natural numbers (Serrazina \& Rodrigues, 2014) and the set of the real numbers (Star \& Newton, 2009; Star et al., 2015).

In Brazil, there is still no local research on cognitive flexibility, although it has motivated researchers to expand knowledge about the numerical cognition of Brazilian children (Dorneles, 2020). This country, located in Latin America, has very different characteristics than European, Asian, and North American nations, which already have a tradition of research in flexibility. Little investment in education, weak educational policies, very few programs of in-service teacher training, and poor distribution of income among citizens are some of the problems that strongly impact Brazilian classrooms (Dorneles, 2019). Although cognitive flexibility approaches are valued in the Brazilian guiding documents of education (Brazil, MEC, 1997, 2017), the teaching of mathematics, in general, is still based on the use of methods that emphasize memorization, standard algorithm procedures, and practices, with limited opportunities for students to verbally express their reasoning (Corso \& Assis, 2017).

In this way, understanding how cognitive flexibility is present in Brazilian children can be an important resource for education professionals in the promotion of effective learning and prevention of difficulties. The research results of Rathgeb-Schnierer and Green (2013, 2015, 2017) show support for the development of mental flexibility in elementary classrooms. These authors propose a new approach for conducting empirical research on mentally flexible strategies and procedures. The present study was conducted based on these authors' research methodology and was designed to examine cognitive flexibility in arithmetic reasoning. It has the objective of evaluating the adequacy of the cognitive flexibility instrument proposed by RathgebSchnierer and Green $(2013,2015,2017)$, for the Brazilian context with second and fourth graders. It also aims to verify whether the sample of Brazilian students exhibits the three profiles of cognitive flexibility in mental calculation found in German and U.S. students, as reported by RathgebSchnierer and Green $(2013,2015,2017)$.

\section{Theoretical Frameworks}

There are multiple conceptual and operational frameworks regarding flexibility (Star \& Newton, 2009), and these reflect different interests and objectives which, consequently, influence the methods for research and data interpretation (Rathgeb-Schnierer \& Green, 2017). Two theoretical frameworks stand out in the research scenario. The first is from cognitive psychology, in which flexible calculation is related to having a repertoire of strategies and choosing and applying an appropriate strategy (Siegler \& Lemaire, 1997; Star, 2005; Verschaffel et al., 2009). The second is from mathematics education, which emphasizes the construction of personal procedures during the solution process, according to the individual's 
knowledge and what a student perceives from the problem (Rathgeb-Schnierer \& Green, 2013, 2015, 2017; Serrazina \& Rodrigues, 2014, 2017; Threlfall, 2002, 2009).

Each theoretical framework implies that cognitive flexibility can be influenced by different variables that will impact the understanding of how this ability is manifested in individuals. Flexible mental calculation can be influenced by characteristics of the mathematical calculus (Blöte et al., 2000; Blöte et al., 2001), by particularities of the individual who is solving the calculation (Siegler \& Lemaire, 1997), and by aspects of the context in which the calculation is being performed (Ellis, 1997; Hatano, 1988). In addition to these variables, some authors associate flexibility with the adequacy of cognitive elements - numerical knowledge and solution procedures - which support the solution process of mental calculations (Rathgeb-Schnierer \& Green, 2013, 2015, 2017; Threlfall, 2002, 2009).

It is noteworthy that, for both theoretical perspectives, learning mathematics will be significant and reasoning will be flexible when conceptual knowledge and procedural knowledge are in interaction (RathgebSchnierer \& Green, 2019). Procedural knowledge is the ability to execute action sequences to solve problems, such as a standard computing algorithm and step-by-step methods. This type of knowledge is linked to specific types of problems and, therefore, is not widely generalizable knowledge. In contrast, conceptual knowledge is an understanding of the principles and relationships of a mathematical domain. This knowledge is not linked to specific types of problems and is therefore more flexible and generalizable (Rittle-Johnson et al., 2001).

With regard to problem characteristics, Blöte et al. (2001) operationalize flexibility as the adequacy of solution strategies for the characteristics of the numbers in a task. Students will be considered flexible solvers of calculations if they choose the optimal solution strategy in relation to the numerical characteristics of the calculation (Blöte et al., 2001). For example, according to the authors, the easiest and most appropriate way to solve " $63-29$ " is to round up the 29 to 30 , subtract 30 from 63 , and then compensate by adding 1 .

In contrast, Threlfall (2009) and Rathgeb-Schnierer and Green (2013, $2015,2017)$ agree that it is possible to perceive and infer, based on personal knowledge, various particularities, and numerical relationships involved in a calculation. However, these inferences about the numbers lead to exploratory attempts that may suggest the necessary steps in the sequence of resolving a calculation. The analysis of the characteristics and numerical relationships of a calculation does not presuppose the use of a pre-determined strategy but sustains the solution process of mental calculation. A recent study by Rathgeb-Schnierer and Green (2017) examined the processes underlying mental calculations in 69 German and US students in the second and fourth grades. The authors verified whether the students recognized the 
characteristics, patterns, and numerical relationships involved in arithmetic calculations and whether they used this knowledge during mathematical reasoning. For Rathgeb-Schnierer and Green (2017), mathematical reasoning is sustained by cognitive elements, which refer to both the solution procedures learned (standard algorithm, decomposing) and to recognized problem characteristics (patterns and numerical relationships). In our view, the first is related to the profile type of rigid reasoning, whereas the second represents the flexibility profile of thought. Thus, analyzing student reasoning is a prime indicator of flexibility in mental arithmetic as a research method. In our study, cognitive flexibility was viewed as a continuous, bi-polar construct, with rigidity at one extreme and flexibility at the other. This operationalization allowed us to measure the students' degree of flexibility through the resolution of their mental calculations.

Rathgeb-Schnierer and Green (2017) found three reasoning profiles: (a) flexible, with a predominance of reasoning by numerical characteristics (over 75\% of the use of this type of reasoning) within a repertoire of 6 to 13 different reasoning; (b) mixed, without clear preference between solution procedures and problem characteristics and repertoire of 2 to 8 reasoning; and (c) rigid, with a preference for solution procedures (over $75 \%$ of the use of this type of reasoning) and repertoire of 1 to 4 different reasoning. These findings indicate that cognitive flexibility is a construct that presents different degrees of development and, therefore, is not an "all or nothing" phenomenon. Comparing countries and school years, statistical differences were found only between the German school years, in which fourth-graders were more flexible than second-graders; the flexibility was credited to the greater familiarity of older students with the types of strategies measured by the instrument.

For Siegler and Lemaire (1997), speed and accuracy primarily determine whether an individual has greater mastery over the procedure. The findings of Torbeyns and Verschaffel (2016) indicated that, among the 58 students of the fourth grade with different levels of mathematical performance, those with high and above-average performance made flexible adjustments to individual problems, that is, they exhibited greater speed and accuracy. In contrast, students with below-average performance did not. Moreover, all students used the standard computing algorithm more frequently than mental calculations, and the authors explain this finding as due to the prestige of the standard procedure in the school context.

At the same time, contextual aspects, derived from socio-cultural lines of research, are indicated by Verschaffel et al. (2009) as more resistant to direct operationalization and experimental control than the other variables, since the choice of strategies reflects the "(...) implicit knowledge about what a given culture defines as appropriate, adaptive, and wise" (Ellis, 1997, p. 492). The contextual aspects listed by Ellis (1997) showed that socio-cultural influences play a powerful role in the formation of repertoires of strategies that individuals have available to solve problems, as well as in the choices that 
they make among the available strategies. Children learn to distinguish the socio-cultural situations in which strategic performance is important: the value of mental solutions versus external aids; independent performance versus the search for help; construction of a positive image in front of peers, teachers, and parents; and maintenance of valued social practices rather than showing an efficient solution behavior. In this sense, beyond metacognitive knowledge, the socio-cultural aspects contribute to the understanding of the choice of strategy, including the one that might seem less effective for the occasion at first sight (Ellis, 1997).

The different characteristics between theoretical perspectives, mentioned above, reflect the many possibilities that cognitive flexibility offers. Each perspective investigates, with a different focus, how having a repertoire of multiple strategies and choosing the most appropriate method of solution can contribute to the promotion of cognitive flexibility (RathgebSchnierer \& Green, 2017). Both perspectives converge on points such as environmental and cultural influences, individual aspects, and the type of knowledge (conceptual or procedural) involved in solving problems. Cognitive psychology and mathematics education have demonstrated the need for teaching mathematics that makes sense and that adapts to the students' context, as opposed to methods based mainly on routine practices unrelated to understanding meaning (Blöte et al., 2000; Blöte et al., 2001; Harnett, 2007; Hatano, 1988).

The study reported here is based on the perspective of mathematics education, highlighting the theoretical framework of Threlfall $(2002,2009)$ and Rathgeb-Schnierer and Green $(2013,2015,2017)$. In this line of research, cognitive flexibility depends on the extent of numerical knowledge, which seems to be more aligned with the objectives of mathematics education nowadays, since it enables the construction of cognitive tools that will sustain the mathematical reasoning throughout the students' schooling process. It is important to emphasize that cognitive flexibility in this study will be examined only with regard to mental arithmetic (Rathgeb-Schnierer \& Green, 2013, 2015, 2017).

\section{Studies on Flexibility}

Contemporary studies on flexibility show some consistent patterns. For example, students who learn standardized calculation methods tend to prefer them, as they offer a safe path for calculation due to their relative simplicity (Blöte et al., 2001; Hatano, 2003; Hatano \& Oura, 2003; Selter, 2001). At the same time, students who choose standard procedures demonstrate limited numerical knowledge (Hatano, 2003, Heirdsfield \& Cooper, 2004; Rathgeb-Schnierer \& Green, 2017) and great difficulty in generalizing this little knowledge (Hatano, 1988). In contrast, individuals who prioritize mental calculation strategies demonstrate a strong conceptual 
understanding of the base-ten decimal system (Varol \& Farran, 2007), of basic facts and fact families (Baroody, 2006), of standards and numerical relations (Ferreira \& Serrazina, 2011; Rathgeb-Schnierer \& Green, 2013, 2015, 2017; Serrazina \& Rodrigues, 2017), as well as a very developed number sense (Hartnett, 2007; Heirdsfield \& Cooper, 2004; Varol \& Farran, 2007).

The literature shows that when students are tied to computing algorithms, they present a rigid or inflexible reasoning profile and the students who demonstrate in-depth numerical knowledge exhibit flexible reasoning (Blöte et al., 2001; Heirdsfield \& Cooper, 2004; Rathgeb-Schnierer \& Green, $2013,2015,2017)$. The third group of children exhibits a mixed reasoning profile incorporating elements of both the rigid and the flexible profiles (Rathgeb-Schnierer \& Green, 2013, 2015, 2017).

Some research suggests that educational emphases centered on different strategies associated with numerical patterns and relationships favor the development of flexibility (Blöte et al., 2001; Rathgeb-Schnierer \& Green, 2019; Star et al., 2015), especially the environments that promote communication, exploration, and comparison of different forms of making mathematics (Ferreira \& Serrazina, 2011; Serrazina \& Rodrigues, 2014, 2017). In this vein, intervention studies and case studies have shown that flexibility exists in a "continuum": the greater the knowledge of multiple strategies (Blöte et al., 2001; Newton \& Star, 2009), the wider is the numerical knowledge (Rathgeb-Schnierer \& Green, 2019; Rechtsteiner-Merz \& Rathgeb-Schnierer, 2015; Serrazina \& Rodrigues, 2014).

Regarding the assessment instruments used to measure cognitive flexibility, more recent studies have demonstrated the validity of verbal reports of individual reasoning because these provide valuable information about the repertoire and use of numerical characteristics, as well as how such cognitive resources can affect the resolution of calculations (Caviola et al., 2018; Rathgeb-Schnierer \& Green, 2015). On the other hand, evidence indicates that the degree of difficulty of the selected calculations may negatively impact the use of flexible strategies in favor of learning computing algorithms (Caviola et al., 2018; Rathgeb-Schnierer \& Green, 2017, Selter, 2001). Subsequently, two studies are examined in detail below because they used this evaluative method to emphasize students' reasoning process.

Heirdsfield and Cooper (2004) studied the mental solution procedures in addition and subtraction multi-digit calculations of six Australian students in the third-grade elementary school. The results showed that flexible students chose and implemented strategies based on a wide numerical comprehension, knowledge of basic facts, metacognition, and belief in their strategies. Inflexible students applied an automatic strategy (mental image of the pencil and paper computing algorithm) to compensate for their limited numerical knowledge.

Caviola et al. (2018) examined how the choices of multi-digit subtraction strategies of 160 Italian children, in third and fifth grades, were 
related to the degree and variations of the complexity of the calculations. Their analysis of the repertoire of strategies indicated that third grade children were more likely to report less efficient strategies (i.e., counting) and depended more on the computing algorithm (from right to left) compared to the fifth-grade children, who used more retrieval of basic facts and strategies from left to right based on concepts (e.g., decomposition).

There is evidence that different teaching methods influence children's mathematical development (Blöte et al., 2001; Mendes, 2012). Flexibility is context-sensitive (Hatano \& Oura, 2003) and, therefore, can vary between individuals from different countries subjected to specific educational contexts. In countries like Germany, Belgium, Italy, and the Netherlands, children learn multi-digit mental calculation in the second grade of elementary school and are introduced to the standard computing algorithm in the third grade (Caviola et al., 2016, 2018; Rathgeb-Schnierer \& Green, 2017). In the United States, less attention is paid to mental calculation (Baroody \& Dowker, 2003), and the standard addition algorithm is introduced in the first grade (RathgebSchnierer \& Green, 2017).

In Brazil, the guiding documents of Education (Brazil, MEC, 1997, 2017) indicate that, in the second grade, children should be able to estimate and compare quantities to establish numerical relations and number patterns that will support them in solving mathematical problems. In the fourth grade, students are expected to improve their strategies for mental and written calculations, relating them to the standard algorithms of mathematical operations. However, Brazilian education is much less systematic about the use of specific instructional approaches for the development of flexibility in mental calculations (Dellatolas et al., 2000), so that standard algorithms, in general, tend to be the only way to teach calculation (Nunes et al., 2005). This point reinforces the need for research on cognitive flexibility to contribute to improving the teaching-learning process of mathematics in Brazil, a country that has many students facing difficulties in mathematics performance (OECD, 2016).

The lack of flexibility studies in Brazil, associated with the relevance of this field of knowledge for mathematics education, motivated the present study. It has the aim of validating: (a) if the methodology to assess cognitive flexibility proposed by Rathgeb-Schnierer and Green (2013, 2015, 2017) can be adequately used with Brazilian elementary students, and (b) if the three profiles of cognitive flexibility reported by Rathgeb-Schnierer and Green $(2013,2015,2017)$, and their relative frequency, can be replicated in Brazilian elementary students. 


\section{Research Design}

\section{Methodology}

Eighty-four students, 42 in second and fourth grades each, from four public schools in the city of Porto Alegre participated in the study. The schools were chosen based on the researchers' convenience and because they presented similarities in the teaching methodology and socioeconomic characteristics.

Initially, 96 students were evaluated using the Arithmetic Subtest of the School Performance Test - TDE (Stein,1994), and only those with average or higher performance were retained for study. Those who failed all calculations in the flexibility instrument were also excluded (RathgebSchnierer \& Green, 2013) resulting in a final sample of 84 students, as shown in Table 1.

Table 1

Sample Characteristics

\begin{tabular}{llll}
\hline Data & Total sample & 2nd grade & 4th grade \\
\hline \multirow{2}{*}{ Sample } & 84 & 42 & 42 \\
& $100 \%$ & $50 \%$ & $50 \%$ \\
Girls & 35 & 18 & 17 \\
& $100 \%$ & $51.42 \%$ & $48.57 \%$ \\
Boys & 49 & 24 & 25 \\
& $100 \%$ & $48.97 \%$ & $51.02 \%$ \\
Mean age (sd) & 9.3 & $8.27(0.35)$ & $10.33(0.40)$ \\
\hline
\end{tabular}

SD: Standard deviation.

\section{Instruments}

\section{Evaluation of Cognitive Flexibility}

For the study reported here, the same interview used by RathgebSchnierer and Green $(2013,2015,2017)$ was translated into Portuguese and used with the Brazilian students. It consists of an interview focusing on the recognition of the characteristics, patterns, and numerical relations of twodigit addition and subtraction problems. Each problem was designed to show at least one special numerical characteristic, such as sum less than 10 , associativity, regrouping, the proximity of the ten, or inverse calculations. The problems were displayed on small cards as shown in Figure 1.

\begin{tabular}{|l|l|l|l|l|l|}
\hline $33+33$ & $73+26$ & $34+36$ & $65+35$ & $56+29$ & $47+28$ \\
\hline $66-33$ & $88-34$ & $95-15$ & $46-19$ & $63-25$ & $31-29$ \\
\hline
\end{tabular}

Figure 1. Calculations of the Flexibility Evaluation Instrument 
The interviews had two phases. In the first phase, the cards were randomly mixed at the table in front of the student, who was encouraged to carefully observe the numbers that comprised each problem and to classify each one as "easy" or "hard" (these labels had been placed on each side of the table). For each classified card, students were asked for a reason: "Why is this problem easy/hard for you?" In the second phase, students were asked to choose problems on each side (easy and hard) and to explain their reasoning about how a mental calculation could be performed to reach a solution.

\section{Arithmetic Performance}

In our study, student arithmetic performance level was measured using the Arithmetic Subtest (AS) of the School Performance Test - TDE (Stein, 1994). This is a standardized instrument for the city of Porto Alegre and consists of 38 questions involving arithmetic calculations with an increasing degree of difficulty. The evaluation was applied collectively in the classroom. TDE scores (Stein,1994) were used as inclusion criteria, and the sample included students with average and high performance in arithmetic, to ensure that the participants presented a good numerical knowledge that would allow them to meet the demands of the research instrument. In the same way, the studies of Rathgeb-Schnierer and Green $(2013,2019)$ also included high and middle achievers.

\section{Data Analysis}

We report both qualitative and quantitative results. A qualitative perspective was considered to be the identification of the reasoning profiles. Accordingly, the interviews were analyzed, and student reasoning was categorized using the coding system developed by Rathgeb-Schnierer and Green $(2013,2015,2017)$. This system consisted of two main categories: reasoning by problem characteristics (RPC) and reasoning by solution procedures (RSP). These central categories included several sub-codes, as shown in Table 2.

\section{Table 2}

Reasoning Coding System

\begin{tabular}{cll}
\hline \multirow{2}{*}{ Category } & $\begin{array}{l}\text { Reasoning by Problem } \\
\text { Characteristics (RPC) }\end{array}$ & $\begin{array}{l}\text { Reasoning by Solution } \\
\text { Procedures (RSP) }\end{array}$ \\
\hline \multirow{5}{*}{ Codes } & Numerical relations & Composing or decomposing \\
& Relations of task & Counting \\
& Analogies of tens and ones & Find the differences \\
& Characteristics of the ones & Modify the problem \\
& Special numbers & Standard algorithm \\
& Size of numbers & Another strategy \\
& Basic facts & \\
\hline
\end{tabular}

Source: adapted from Rathgeb-Schnierer and Green $(2013,2015,2017)$ 
Reasoning by problem characteristics was coded when students specifically referred to the characteristics of the problem (for example, the double and half relation of 66-33), thereby utilizing flexible reasoning. Reasoning by solution procedures was coded when students described any mental computing or step-by-step technique (counting, decomposing, standard algorithm) and were classified as rigid reasoning. In this way, the identification of the flexibility profiles was based on the qualitative analysis of the frequency (the number of times the reasoning is used) and repertoire (the variety of reasoning used) of student reasoning. Subsequently, a quantitative analysis involved non-parametric techniques - Kruskal-Wallis and Wilcoxon ranked sum tests - at a significance level of $5 \%$, to provide statistical evidence of each reasoning profile and comparisons between them. In the KruskalWallis test, there are two degrees of freedom, when three profiles are compared. In this study, the sample of second and fourth grades was combined, to achieve statistical power in the comparisons between three flexibility profiles.

\section{Results}

The second and fourth graders produced 2,420 valid reasoning during the sorting task. Of this total, 57 percent were categorized as problem characteristics and 43 percent as solution procedures. When problem characteristics were used to classify ("easy" or "hard") and resolve the problems, the students' reasoning referred predominantly to basic facts (39\%) and the characteristics of the ones (17\%) (e.g., the sum adds up to ten, fives at the ones place and verifying the need or not of regrouping). When the reasoning by solution procedure was used, the preference was for the standard computing algorithm (44\%) and counting (42\%).

The data show that the sorting and interview generated sufficient reasoning that could be coded using the Rathgeb-Schnierer \& Green (2013, 2015, 2017) scheme. Figure 2 shows additional details about students' calculation accuracy across the 12 problems. In the box-plot graph, the center of the distribution is indicated by the heavy median line located inside the box, which divides half of the data. Below the median are the students who obtained fewer correct answers in the calculation task, and above are the students who got more calculations right. The range indicates the minimum and maximum limits of correct calculations in each group, represented by the horizontal lines at the limits of each graph. Finally, the circles beyond these limits represent two students who presented discrepant performance, the outliers. 


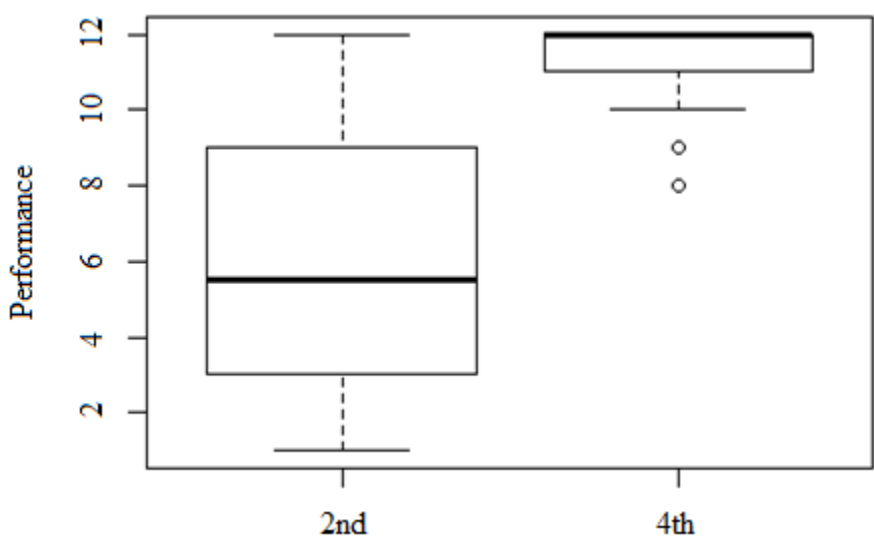

Figure 2. Number of Correct Computations for Two Groups of Students

Students were classified as flexible or rigid using the profiles reported in Rathgeb-Schnierer and Green (2017). In the flexible profile, there was a predominance of reasoning by problem characteristics (RPC) at the expense of reasoning by solution procedure (RSP). In the rigid profile, it was the reverse, with a predominance of reasoning by solution procedures.

Students exhibiting a rigid reasoning profile $(n=15)$ showed very low frequency and repertoire metrics. The reasoning by problem characteristics was slightly lower than the reasoning by solution procedure. The main strategy of this group was counting, while basic facts were little used. Students exhibiting a mixed reasoning profile $(n=53)$ presented the greatest diversity of reasoning. Although their RPC stood out, the rates of RSP use were also high. For example, the use of a standard computing algorithm and counting was as high as the use of basic facts, characteristics of the ones, and relations of tasks. Finally, students who exhibited a flexible reasoning profile $(n=16)$ had equally high metrics for both ratios, thereby demonstrating a connection between repertoire and frequency. In the mixed profile group, problem characteristics were used two times more than solution procedures. These students used all the strategies categorized as RPC described in Table 2, but they also used a standard computing algorithm in some calculations.

Table 3 shows frequency data for reasoning categories and student profiles. Note that students classified as flexible exhibited a higher median and greater range in reasoning about problem characteristics than solution procedures $(W=252, p<.0001)$. In contrast, mixed students produced the greatest variability in reasoning about both problem characteristics and solution procedures. These students' medians reflected more of a balance in reasoning attributed to the two categories, even though the median for problem characteristics is higher than for solution procedures $(W=1789.5, p$ $=0.0149$ ). Rigid profile students presented a very restricted reasoning pattern, as demonstrated by the reduced ranges that reflect statistically equivalent medians $(W=82, p=0.2053)$. 
Table 3

Reasoning Frequencies in Two Categories and Three Profiles

\begin{tabular}{lllllll}
\hline \multirow{2}{*}{ Reasoning } & \multicolumn{2}{l}{ Flexible } & \multicolumn{2}{l}{ Mixed } & \multicolumn{3}{l}{ Rigid } \\
\cline { 2 - 7 } & MD & RNG & MD & RNG & MD & RNG \\
\hline $\begin{array}{l}\text { Problem } \\
\text { characteristics }\end{array}$ & 23 & $16-31$ & 17 & $8-35$ & 2 & $2-6$ \\
$\begin{array}{l}\text { Solution } \\
\text { procedures }\end{array}$ & 13 & $8-18$ & 15 & $6-23$ & 3 & $1-10$ \\
\hline
\end{tabular}

MD: median; RNG: range.

Besides frequency, the repertoire (i.e., the number of different strategies used) is an important feature of the reasoning profiles. Repertoires are shown in Table 4. Data on the repertoire of both problem characteristics and solution procedures are aligned with the frequency data. That is, these categories exhibit the same patterns reported for frequency data (i.e., different for the flexible and mixed reasoning profiles and equivalent for the rigid profile).

Table 4

Reasoning Repertoire by Two Categories and Three Profiles

\begin{tabular}{lllllll}
\hline \multirow{2}{*}{ Reasoning } & \multicolumn{2}{l}{ Flexible } & \multicolumn{2}{c}{ Mixed } & \multicolumn{3}{c}{ Rigid } \\
\cline { 2 - 7 } & MD & RNG & MD & RNG & MD & RNG \\
\hline $\begin{array}{l}\text { Problem } \\
\text { characteristics }\end{array}$ & 6 & $3-7$ & 5 & $3-7$ & 2 & $0-3$ \\
$\begin{array}{l}\text { Solution } \\
\text { procedures }\end{array}$ & 2 & $2-5$ & 3 & $1-5$ & 2 & $1-3$ \\
\hline
\end{tabular}

MD: median; RNG: Range.

The reasoning frequency data by problem characteristics and solution procedures are presented in Figures 3 and 4, respectively. These box-plot graphs demonstrate the reasoning distribution in each flexibility profile.

Figure 3 displays students' reasoning in the category of problem characteristics. A Kruskal-Wallis test revealed the presence of at least one significant difference between groups $(H=41.703, d f=2, p<0.0001)$. Consequently, differences between group medians were assessed using the Wilcoxon Signed Rank test. Flexible students used significantly more reasoning by problem characteristics than mixed students $(W=617, p<$ 0.0061 ), and mixed students used significantly more such reasoning than rigid students $(W=795, p<0.0001)$.

Reasoning categorized as solution procedures, shown for the three groups in Figure 4, was similarly evaluated. A Kruskal-Wallis test showed the presence of at least one significant difference $(H=35.013, d f=2, p<0.0001)$ between profile groups. Consequently, a second Wilcoxon Signed Rank test was conducted. Its results reflected a different performance pattern than for 
reasoning by problem characteristics. For reasoning by solution procedures, flexible and mixed profile students were statistically equivalent $(W=331.5, p$ $=.1895$ ). In contrast, students with rigid profiles scored significantly lower than flexible students $(W=237.5, p<.0001)$ and mixed students $(W=777.5$, $p<.0001)$.

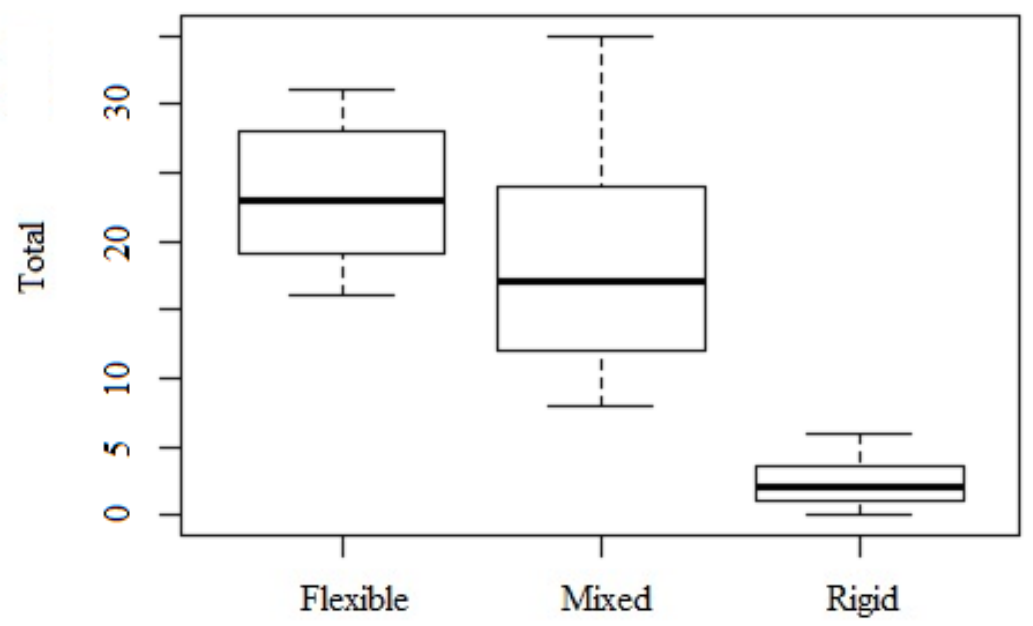

Figure 3. Frequency of Reasoning by Problem Characteristics

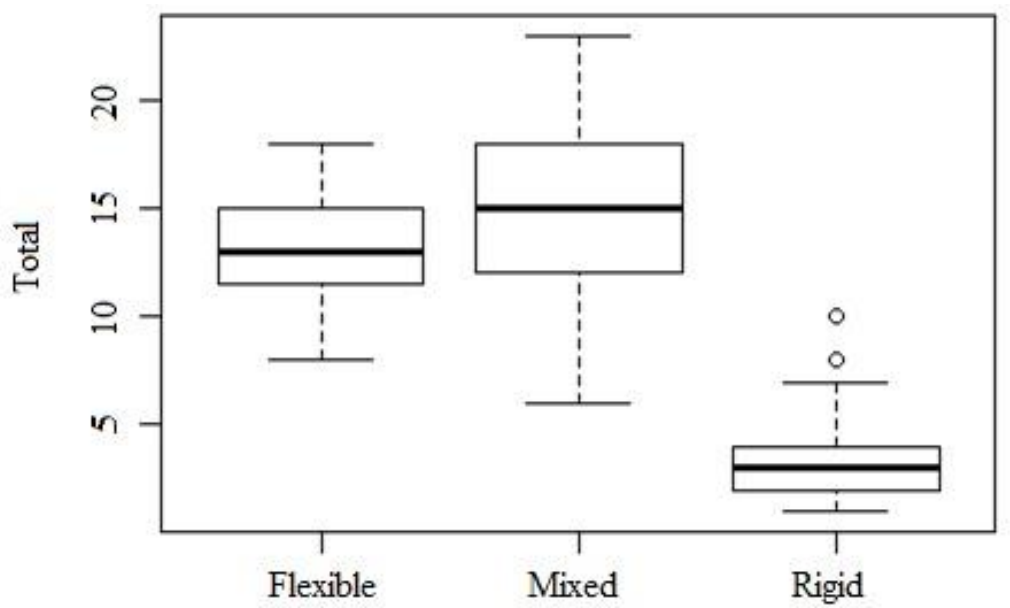

Figure 4. Frequency of Reasoning by Solution Procedures

\section{Discussion}

This study attempted to determine (a) the adequacy of the RathgebSchnierer and Green $(2013,2015,2017)$ methodology for assessing cognitive flexibility in second and fourth-grade Brazilian students, and (b) the extent to which the Rathgeb-Schnierer and Green $(2013,2015,2017)$ profile patterns of cognitive flexibility could be replicated. 
In relation to the first objective, results showed that the sorting task was effective in eliciting children's reasoning, with a total of 2,420 reasoning being categorized. The method of asking children to classify two-digit addition and subtraction problems and then to discuss their reasoning was successful for the Brazilian sample. This result is noteworthy, considering that these students are generally not encouraged to reflect on numbers and their characteristics and patterns. It is also worth mentioning that the interviews strongly encouraged students to talk about their mathematical reasoning, a practice that is not emphasized in Brazil. In the beginning, many children tried to demonstrate their mathematical expertise by giving only the final result of the problem, without showing their reasoning path, as if they calculated automatically. As they became familiar with the dynamics of the interview task, they gave more information about strategies and numerical knowledge they used. Most of the children explained in detail their steps in solving problems. Such responsiveness helps explain the high frequencies of reasoning reported for the sample since all coherent responses were counted. These results support the validity of the instrument in producing relevant and repeatable sorting and solution strategies for two-digit arithmetic problems (Caviola et al., 2018; Rathgeb-Schnierer \& Green, 2015, 2017). In addition to being an effective method for identifying cognitive flexibility, the interview task is a good pedagogical tool for encouraging students' thinking processes while doing arithmetic calculations, and in that vein, it can be considered a promising approach to mathematics education in elementary classrooms (Rathgeb-Schnierer \& Green, 2019; Rechtsteiner-Merz \& Rathgeb-Schnierer, 2015).

It is important to note that a discrepancy in performance was found between the two school grades in the solution calculations of the research instrument's problems. Specifically, the performance of the second graders was significantly lower than fourth-graders, and this discrepancy reflected the difficulty of two-digit arithmetic for these students. This situation generated little data on the reasoning of the second graders, which may have influenced the final results of the investigation since the group of students with rigid reasoning consisted exclusively of second-grade students. In this sense, it is possible to say that the cognitive flexibility instrument used by RathgebSchnierer and Green $(2013,2015,2017)$ can be adapted to the Brazilian sample. However, the two-digit problems (level of difficulty) were more appropriate for the Brazilian fourth graders. Researchers call attention to the fact that it is fundamental to adapt the degree of difficulty of the calculations of the instrument so as not to negatively impact the research results (Caviola et al., 2018; Selter, 2001). Therefore, the influence of the evaluation instrument on the second graders' results can be considered a limitation of this study.

Concerning the second objective of this investigation, data analysis showed that the three reasoning profiles (flexible, mixed, and rigid) were 
replicated in the Brazilian sample. Both metrics of repertoire and frequency, for the two kinds of reasoning (RPC and RSP), complemented each other in the children's reasoning. The repertoire data offered an important clarification of the frequency data, because, for example, a student may have high frequency but low repertoire (no variation in reasoning). Similarly, reasoning frequency may have been the primary factor in the significant effect of each profile, because an isolated frequency datum may have masked the variability of the children's reasoning (Rathgeb-Schnierer \& Green, 2017).

The frequency and repertoire data were also proportional in each profile. For example, the flexible profile had a greater range and median of reasoning by problem characteristics compared to reasoning by solution procedures, and this was true for both frequency and repertoire. The other groups also followed this pattern, with the rigid profiles showing low frequency and repertoire values, and the mixed profile showing high values for both types of reasoning. Although there was alignment between the two indicators, the frequency values were much higher than the repertoire, due to the students' unexpected motivation to demonstrate their knowledge for solving the problems. This shows that if we considered only the frequency of reasoning of the Brazilian children, we could have inferred that they were more flexible than the American and German ones, as the Brazilians presented a range of 2 to 35 reasoning by problem characteristics (in the total sample), while Rathgeb-Schnierer and Green (2017) reported a 0 to 17 range of reasoning in their German and American students. A different pattern occurred with the repertoire data, where the students of Rathgeb-Schnierer and Green (2017) presented a range of 0 to 11 of reasoning by problem characteristics, while the Brazilian sample showed a repertoire range of 0 to 7. These comparisons between countries are qualitative and serve to validate the use of frequency and repertoire as indicators of flexibility profiles, as proposed by Rathgeb-Schnierer and Green (2017). Furthermore, the variability of reasoning demonstrated by the Brazilian students' repertoires, seems to better reflect the concept of flexibility than the number of times that a certain type of reasoning occurs (frequency).

Statistical analyses confirmed that the flexible, mixed, and rigid profiles in the Brazilian sample were aligned with the criteria proposed by Rathgeb-Schnierer and Green $(2015,2017)$, in which the flexible profile is characterized by the predominance of reasoning by problem characteristics (RPC) and dynamic performance. When the basis of the reasoning was the solution procedures (RSP) and step-by-step computations, the students' reasoning was considered rigid. And the students with mixed reasoning present a mixture of reasoning by problem characteristics and by solution procedures.

Students with flexible reasoning (eight in second grade and eight in fourth grade) focused their reasoning on problem characteristics, with remarkable variety and frequency of arguments in this category; however, 
when they reasoned about solution procedures, their thought was more restricted and, thus presented a significant difference between RPC and RSP reasoning. Students with mixed reasoning (19 in second grade and 34 in fourth grade) comprised the largest group and the most difficult to characterize because the children presented different performances among themselves: some had a preference for RPC, others for RSP, and still others presented high frequency and reduced reasoning repertoires. In this sense, the medians similar to the flexible profile were due to the great variability of reasoning that composed the mixed profile. Finally, students with rigid reasoning (16 in second grade) presented balanced reasoning between RPC and RSP, indicating a slight trend toward the latter, within a range of fairly restricted reasoning. However, our data on the rigid profile must be interpreted considering the limitation of the flexibility evaluation instrument that will be later discussed.

Of the total number of students, 19 percent were described as flexible, 18 percent as rigid, and most (63 percent) presented a mixture of rigid and flexible reasoning. These findings corroborate evidence found in the literature, which states that flexibility has a continuous character (i.e., it is not about having the flexibility or not, but it seems to exist on a continuum across individuals). Therefore, the results presented in this study confirmed the replication, in the Brazilian sample, of the three patterns of cognitive profiles (and the general characterization of each one) described by Rathgeb-Schnierer and Green $(2013,2015,2017)$ with German and U.S. students from second and fourth grades.

Although it was not an objective of this study to compare and verify the kind of strategies used by the different samples, it seems that the strategies used by Brazilian children were similar to those reported by RathgebSchnierer and Green (2017). Those authors reported that 54.5 percent of the reasoning of their sample were coded as reasoning by problem characteristics, and 31.5 percent as reasoning by solution procedure. In Brazil, 57 percent of the reasoning were coded as problem characteristics, and 43 percent as solution procedures. Although numerical knowledge stood out in our results, the solution procedures also showed high rates and revealed the weaknesses of this knowledge in Brazilian students. That is, of all reasoning by solution procedure in the sample, the highest frequencies were found for counting $(42 \%)$ and the standard algorithm (44\%). In the German and American samples, when children solved the calculations by solution procedure, the use of the composition and decomposition strategy appeared frequently (RathgebSchnierer and Green, 2017). For Brazilians, this strategy was in third place for the RSP category and was more frequent among flexible and mixed students. In contrast, in America and Germany, the use of composition and decomposition characterized the rigid reasoning group. In the Brazilian educational context, composition and decomposition reasoning strategy is considered a more sophisticated one, in relation to counting, for example, and 
is still poorly developed in elementary school classrooms. We believe that the study of cognitive flexibility expands the understanding of flexibility profiles in Brazilian students, differentiating them from German and American samples, and also underscores the limits of mathematics education in Brazil that primarily focuses on memorization procedures. When strategies based on numerical knowledge are limited or offer little support for reasoning, children use the ones that they know and feel safe with (Threlfall, 2002) to achieve a calculation solution.

\section{Educational Consideration}

In educational terms, when one knows and identifies the students' reasoning profiles, one provides teachers with a broad view of the numerical knowledge of their students and, therefore, they can outline a pedagogical intervention plan that promotes more sophisticated and flexible levels of mathematical thinking. To promote cognitive flexibility, we believe that the same approach of sorting problems and reasoning about how they are solved can be used as a pedagogical resource because this approach enables the reflection and awareness of the students' knowledge of problem characteristics and numerical relations (Rathgeb-Schnierer \& Green, 2019).

Teachers can raise cognitively challenging questions to encourage students to reflect and make them reason about their choices (for example, "Is this calculation easy or difficult for you? Why?"; "Are there any easy operations that help you to solve those that are more difficult?"). Actions of this type imply delaying the teaching of standard computing algorithms in favor of the approach that prioritizes the analysis of the characteristics of operations and the relationships between operations (Rathgeb-Schnierer \& Green, 2019). The attentive mediation of the teacher, inviting students to intentionally reflect on different aspects of numerical competence (numbers and operations, strategic means, numerical patterns, numerical relations), with a focus on cognitive flexibility, would provide students with the opportunity to establish their numerical discoveries which will ultimately enrich the later learning of basic facts and computing algorithms (which rote memorization cannot do). In other words, through interventions of this kind, teachers can foster the development of their students' metacognitive competences (Efklides \& Vlachopoulos, 2012; Flavell, 1979) in a way that students are invited to think about their thinking processes and to reflect on the most appropriate tools for problems solution. Thus, when the procedures are introduced step by step (as the composing and decomposing strategies, for example), there will be an important conceptual basis for understanding procedural knowledge, which will, in turn, favor more flexible solutions later on. The focus on teaching a variety of problem-solving strategies has to be emphasized. Moreover, specific efforts have to be directed towards encouraging students to 
reflect on and reason about computational problems if more advanced levels of flexible reasoning are to be reached in Brazil.

This study introduces the approach of flexibility in mental calculations to the Brazilian field of study, which can shed light on this important mathematical ability in the field of teacher training. There is no doubt that further research is necessary to broaden our knowledge of flexibility profiles in Brazilian students, as well as to verify the adequacy of the instruments designed to assess flexibility for different schooling years. Also, to expand the understanding of this construct, research is needed that assesses the relationship between flexibility in mental calculation and domain-specific skills (such as number sense) and domain-general skills (working memory, for example). Longitudinal studies that track the development of flexibility during the schooling process are urgently needed.

\section{References}

Baroody, A. J. (2006). Mastering the basic number combinations. Teaching Children Mathematics, 23, 22-31.

Blöte, A. W., Klein, A. S., \& Beishuizen, M. (2000). Mental computation and conceptual understanding. Learning and Instruction, 10(3), 221-247.

Blöte, A. W., Van der Burg, E., \& Klein, A. S. (2001). Students' flexibility in solving two-digit addition and subtraction problems: Instruction effects. Journal of Educational Psychology, 93(3), 627-638.

Brasil, M. E. C. (1997). BRASIL. Ministério da Educação (MEC). Parâmetros curriculares nacionais: Matemática. MEC/SEF.

Brasil, M. E. C. (2017). BRASIL. Ministério da Educação (MEC). Base Nacional Comum Curricular. MEC/SEB.

Caviola, S., Mammarella, I. C., Pastore, M., \& LeFevre, J. A. (2018). Children's strategy choices on complex subtraction problems: Individual differences and developmental changes. Frontiers in Pychology, 9, 1-16.

Corso, L. V., \& Assis, É. F. (2017). Reflexões acerca da aprendizagem inicial da matemática: Contribuições de aspectos externos ao aluno. In L. Piccoli, L. V. Corso, S. S. Andrade, \& R. Sperrhake (Eds), Pacto nacional pela alfabetização na idade certa PNAIC UFRGS: Práticas de alfabetização, aprendizagem da matemática e políticas públicas, (pp. 114-138). Oikos.

Dellatolas, G., von Aster, M., Willadino-Braga, L., Meier, M., \& Deloche, Z. (2000). Number processing and mental calculation in school children aged 7 to 10 years: A transcultural comparison. European Children \& Adolescent Psychiatry, 9(2), 102-110.

Dorneles, B. V. (2019). Mathematical learning and its difficulties in LatinAmerican countries. In A. Fritz, V. Haase, \& P. Räsänen (Eds.), 
International handbook of mathematical learning difficulties (pp. 201-212). Springer.

Dorneles, B. V. (2020). Cognición numérica em Brasil:Una revisión de um campo de investigación em Desarrollo [Numerical cognition in Brazil: A narrative review of a growing research field]. Studies in Psychology, 41(2), 271-293.

Efklides, A., \& Vlachopoulos, S. P. (2012). Measurement of metacognitive knowledge of self, task, and strategies in mathematics. European Journal of Psychological Assessment, 10(3), 227-239.

Ellis, S. (1997). Strategy choice in sociocultural context. Developmental Review, 17(4), 490-524.

Ferreira, E., \& Serrazina, L. (2011). Strategies and procedures: What relationship with the development of number sense of students? In Proceedings of the Seventh Congress of the European Society for Research in Mathematics Education(pp. 307-315). Rzeszów, Poland: University of Rzeszów, Poland.

Flavell, J. H. (1979). Metacognition and cognitive monitoring: A new area of cognitive-developmental inquiry. American Psychologist, 34(10), 906-911.

Hartnett, J. (2007). Categorisation of mental computation strategies to support teaching and to encourage classroom dialogue. In J. Watson \& $\mathrm{K}$. Beswick (Eds). Mathematics: Essential research, essential practice (pp. 345-352). MEGA

Hatano, G. (1988). Social and motivational bases for mathematical understanding. New Directions for Child Development, 41, 55-70.

Hatano, G. (2003). Foreword. In A. J. Baroody \& A. Dowker (Eds.). The development of arithmetic concepts and skills (pp. 11-13). Erlbaum.

Hatano, G., \& Oura, Y. (2003). Reconceptualizing school learning using insight from expertise research. Educational Researcher, 32(8), 2629.

Heirdsfield, A. M., \& Cooper, T. J. (2004). Factors affecting the process of proficient mental addition and subtraction: Case studies of flexible and inflexible computers. The Journal of Mathematical Behavior, 23(4), 443-463.

Mendes, M.F. (2012). A aprendizagem da multiplicação numa perspectiva de desenvolvimento do sentido de número: Um estudo com alunos do 1. ${ }^{o}$ ciclo (Tese de Doutorado). Instituto de Educação da Universidade de Lisboa, Lisboa, Portugal.

Newton, K. J., \& Star, J. R. (2009). Exploring procedural flexibility in struggling algebra students. In 31st Annual meeting of the North American chapter of the International Group for the Psychology of Mathematics Education (pp. 210 - 217). Atlanta, GA.

Nunes, T., Campos, T. M. M., Magina, S., \& Bryant, P. (2005). Educação matemática: Números e operações numéricas. Cortez. 
OCDE. (2016). PISA 2015 assessment and analytical framework: Science, reading, mathematic and financial literacy. PISA 2015 Mathematics Framework. OECD Publishing.

Rathgeb-Schnierer, E., \& Green, M. (2013). Flexibility in mental calculation in elementary students from different math classes. In B. Ubuz, Ç. Haser, \& M. A. Mariotti (Eds.). Proceedings of the Eighth Congress of the European Society for Research in Mathematics Education (pp. 353-362). Middle East Technical University.

Rathgeb-Schnierer, E., \& Green, M. (2015). Cognitive flexibility and reasoning patterns in American and German elementary students when sorting addition and subtraction problems. In K. Krainer, \& N. Vondrová (Eds.), CERME 9-Ninth Congress of the European Society for Research in Mathematics Education(pp. 339-345). Prague: Czech Republic.

Rathgeb-Schnierer, E., \& Green, M. (2017). Profiles of cognitive flexibility in arithmetic reasoning: A cross-country comparison of German and American elementary students. Journal of Mathematics Education, 10(1), 1-16.

Rathgeb-Schnierer, E., \& Green, M. G. (2019). Developing flexibility in mental calculation. Educação \& Realidade, 44(2), 1-17.

Rechtsteiner-Merz, C., \& Rathgeb-Schnierer, E. (2015). Flexible mental calculation and "Zahlenblickschulung". In CERME 9-Ninth Congress of the European Society for Research in Mathematics Education (pp. 354-360). Prague, Czech Republic.

Serrazina, M. D. L., \& Rodrigues, M. (2014). A tarefa como instrumento de desenvolvimento da flexibilidade de cálculo.GD1-Design de Tarefas, 1, 109-120.

Serrazina, M. D. L., \& Rodrigues, M. (2017). 'Day number': A promoter routine of flexibility and conceptual understanding. Journal of Mathematics Education, 10, 67-82.

Selter, C. (2001). Addition and subtraction of three-digit numbers: German elementary children's success, methods and strategies. Educational Studies in Mathematics, 47(2), 145-173.

Siegler, R. S., \& Lemaire, P. (1997). Older and younger adults' strategy choices in multiplication: Testing predictions of ASCM using the choice/no-choice method. Journal of Experimental Psychology: General, 126(1), 71-92.

Star, J. R. (2005). Reconceptualizing procedural knowledge. Journal for Research in Mathematics Education, 36(5), 404-411.

Star, J. R., \& Newton, K. J. (2009). The nature and development of experts' strategy flexibility for solving equations. ZDM - The International Journal on Mathematics Education, 41(5), 557-567.

Star, J. R., Newton, K., Pollack, C., Kokka, K., Rittle-Johnson, B., \& Durkin, K. (2015). Student, teacher, and instructional characteristics related 
to students' gains in flexibility. Contemporary Educational Psychology, 41, 198-208.

Stein, L. M. (1994). TDE: Teste de desempenho escolar: Manual para aplicação e interpretação (pp. 1-17). Casa do Psicólogo.

Threlfall, J. (2002). Flexible mental calculation. Educational Studies in Mathematics, 50 (1), 29-47.

Threlfall, J. (2009). Strategies and flexibility in mental calculation. ZDM-The International Journal on Mathematics Education, 41(5), 541-555.

Torbeyns, J., De Smedt, B., Peters, G., Ghesquiere, P., \& Verschaffel, L. (2011). Use of indirect addition in adults' mental subtraction in the number domain up to 1,000. British Journal of Psychology, 102(3), 585-597.

Torbeyns, J., \& Verschaffel, L. (2016). Mental computation or standard algorithm? Children's strategy choices on multi-digit subtractions. European Journal of Psychology of Education, 31(2), 99-116.

Varol, F., \& Farran, D. (2007). Elementary school students' mental computation proficiencies. Early Childhood Education Journal, 35(1), 89-94.

Verschaffel, L., Luwel, K., Torbeyns, J., \& Van Dooren, W. (2009). Conceptualizing, investigating, and enhancing adaptive expertise in elementary mathematics education. European Journal of Psychology of Education, 24(3), 335-359.

\section{Authors:}

Sula Cristina Teixeira Nunes, $\mathrm{PhD}$ student, Post Graduate Program of Education, Universidade Federal do Rio Grande do Sul, Porto Alegre, Brazil. E-mail: sulactn@gmail.com

Beatriz Vargas Dorneles, Full Professor in the Department of Specialized Studies, Post Graduate Program of Education, Universidade Federal do Rio Grande do Sul, Brazil. E-mail: beatriz.dorneles@ufrgs.br

Luciana Vellinho Corso, Professor in the Department of Specialized Studies, Post Graduate Program of Education, Universidade Federal do Rio Grande do Sul, Brazil. E-mail: luciana.corso@ufrgs.br 